\title{
Effect of Cloud Computing Systems in Terms of Service Quality of Knowledge Management Systems
}

\author{
Hamed Rezaei, Behdad Karimi, and Seyed Jamalodin Hosseini
}

\begin{abstract}
Nowadays, information Systems play effective role in the organizations in a way that they cannot be imagined without these systems. On the other hand knowledge value of organizations are increasing and they prefer to take care of this knowledge. Accordingly, having a knowledge management system that can handle this task is very important. Based on one of the successful models of information systems, management system includes such major factors each one focusing on a part of the system. Meanwhile cloud computing technology has created a revolution in software and hardware processing. So in this paper we try to evaluate the success rate of "Quality of Service" which is one of the major factors of management system based on cloud computing on a higher education system.
\end{abstract}

Index Terms-Knowledge management systems, cloud computing, service quality.

\section{INTRODUCTION}

Nowadays, the new technologies play a widespread role in the world. That is because of its ability to solve everyday problems of many people in addition to decreasing living expenses. As [1] mentions in his article, technology has managed to release IT based companies from exorbitant costs. One of these technologies is cloud computing which has been officially established since 2006. The improvement of this technology has been in such a way that [2] considers it as one of the most important concepts in information technology field. To define the cloud computing in a right way, the best definition is the one that United States National Standards Institute presents [3]: cloud computing is a safe and accurate framework to access different sources of network, such as servers, functional applications, etc. Which could be provided for the users so fast and with minimum costs and efforts.

On the other hand [4] claims that the cloud computing and online social networks are suitable platforms to set up the knowledge management systems. Therefore, by expansion of knowledge based organizations, many different studies have been done on the knowledge management systems. According to [5]'s definition, knowledge management systems play a basic role in the system which is defined as: providing an intelligent backup of different users in the organization that play important roles in organizational knowledge graph. One of the most important benefits of these knowledge management systems is to cause the company to obtain a

Manuscript received August 1, 2014; revised November 4, 2014.

Hamed Rezaei and Behdad Karimi are with the Department of Engineering, Faculty of Information Technology, University of Qom-Iran, Iran (e-mail: Hamed.rezaei1368@aol.com)

Seyed Jamalodin Hosseini is with the Department of Engineering, Member of Faculty of Industrial Engineering, University of Qom-Iran, Iran. competitive advantage. Moreover, it can cause an increase in work and system quality and speed up the knowledge manufacturing cycle [6]. Therefore, knowledge management systems need a software platform to present their services to company employees for producing, modifying and maintaining of knowledge.

In this article we are to investigate the uploading result of a knowledge management system using the cloud computing technology. The main question is whether this new knowledge management system can cause a proper result on the quality of services or not? In the next section we will take a short look at the history of the study, then we will hint the successful model of information systems and in the next part a general introduction will be presented about cloud computing technology and finally we will describe the results.

\section{BACKGROUND OF RESEARCH}

Delone and Mclean [7], [8] in 1992 and 2003 presented reference model for evaluating and measuring the success of the information system, many researches have been done on their reference model. Most of researchers measured their work based on accuracy of Delone and Mclean model or according to their model examine various examples of information systems. One of the dimensions of this model is quality of service that can play the most important role in the information system success. Accordingly [9]-[12] mention this point that success of information system can lead to success of organization. In order to assess this presented model, extensive researches have been done. For example [13] in his research, has extended this model to E-learning system and evaluated the success of system with 6 major factors. In this paper the researcher has precisely used the presented model by [8] and test the accuracy of the model in E-learning system by designing many hypotheses. The results show that the entire early model works correctly. On the other hand various researchers focused their attention on one of the presented model by [8]. For instance, [14] only focused on assessing the satisfaction of customers of the institute. Also tried to extend the success of entire information system to customer satisfaction. The research is based on this hypothesis that relationships seen in figure 1 which either lead to or predicated from user satisfaction, are true or false. At the end the result confirms the validity of the hypothesis. In this regard, other researches could be outlined [15], and [16].

Due to the extensive focus on the aspects of success in information systems, unfortunately there is no special attention to quality of service factor. Meanwhile evaluating of this factor is important. Although knowledge management systems will have many benefits for organizations, [17] 
however knowledge management systems as well as many computer systems might be in trouble. May this problem root in poor user interface or other defects [18], the researcher have decided more thorough discussion of this issue and analyzed a real sample.

\section{A. Success Model of Information Systems}

As stated in background of research this research is based on Delone \& Mclean model. In this model 6 important factors are assessed to determine the success of an information system as follows:

1) System Quality

2) Information Quality

3) Service Quality

4) System Usage

5) User Satisfaction

6) net benefits

These 6 factor are connected to each other as presented in figure one [7]. As can be seen in Fig. 1, service quality is one of the factors of organization measurement that somehow other factor can be derived from. To verify this issue, we can mention the research that is done before by [19] which considers service quality factor as an important factor for organizations that work in the field of business and e-commerce. Other factors are also important but in today's world quality service is the main criteria for assessing a system. For example in this regard USE factor in contrast of Service Quality is ineffective and declares that the Quality Service is one of the most important success factors. The use of knowledge management system is significantly related to the success of the factor in ensuring high quality of the information system. On the other hand the system is mostly depended to the same quality of service. One of the researches that can be done is measuring the success model of information systems. In the other words, whether your model is correct or not many researches have been done about this topic [20]. Also from the second page different factors can be assessed one by one [21]. Totally, if one information system that is measured by all 6 factors could pass in each factor measurement, that system would be a successful system.

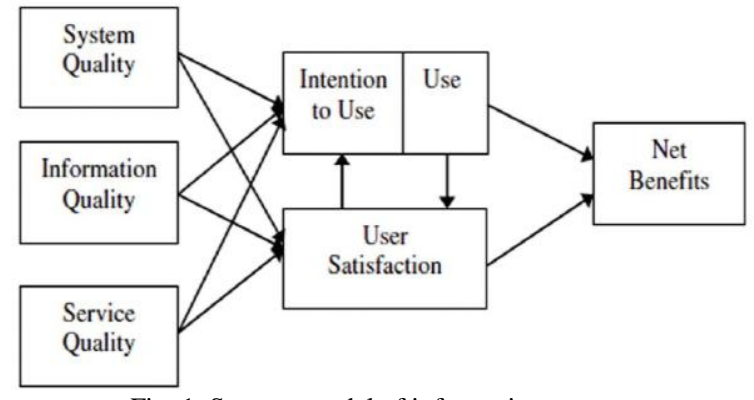

Fig. 1. Success model of information system.

\section{B. Cloud Computing}

According to the introduction, cloud computing is a successful new technology. This technology can be explained as follows: Paying to an external company to run applications and store their results rather than running these application locally on the systems of the company. It is called cloud computing. [22]

Almost all the international reliable sources divide the cloud services into 3 categorizes [22] - [24].

1) Software as a Service (Saas)

2) Platform as a Service (Paas)

3) Infrastructure as a Service (Iaas)

Software as a Service (SaaS): SaaS refers to systems that can receive, process, and then deliver applications and system software via network (Internet/Intranet/Extranet). Examples of SaaS include: Email systems and business data processing systems such as CRM / ERP. This section is an important part of cloud technology.

SaaS Production Platform: Providing all required resources of an organization on a server to run its applications without the need to download or install the software is called Platform as a Service (PaaS) [24]. This section is most commonly used by programmers and developers. Obvious examples of this service is Google Gears.

Infrastructure as a Service: When it comes to the discussion of software technologies, of course a suitable hardware infrastructure is required on which the software could be run properly. Taking possession of or renting processor time, storage media, network capacity, and other critical requirements of an organization, from an external server is known as "using the infrastructure of the executing company "which is available to the company as a service [24].

\section{HYPOTHESIS}

The main hypothesis of this research is that after loading the appropriate cloud server to provide a comprehensive knowledge management system, the system quality will get acceptable score by users. To be more precise, our main hypothesis is that if using a cloud server system increases the quality of service of a knowledge management system or not. We will continue to investigate the validity of this hypothesis.

\section{DISCUSSION}

\section{A. Case Study}

As mentioned in the previous section, the purpose of this research is to evaluate the quality of a knowledge management system based on cloud technology. To achieve this goal, we have examined one of the higher education institutions that works in the field of network engineering.

In this institute, we have considered 30 students, which is 2 classes of 15 members. The students first used the traditional knowledge management system so that they tried to solve their own or their organization problems through sending email or making phone calls to the experts. At this stage, a questionnaire was provided to these 30 participants in order to measure the system's quality of service. After collecting the questionnaires, a knowledge management system (KMS) is designed and produced in which users do not need to install any applications, but the applications are only run on the server and the users can leave comments and express their problems and questions and store the results for further applications.

After about 60 days, the second questionnaire was given to the same statistical population. The two classes were chosen 
in such a way that they were continued by the time the second questionnaire was distributed. This questionnaire included several questions related to the user comments and their satisfaction level of the system and the answers were categorized in 5 response options from strongly agree to strongly disagree. In the next section we will examine the statistical results obtained from these questionnaires.

\section{B. Statistical Results}

A situation summary of the participants in this study is shown in Table I.

TABLE I: RESPONDENTS ACCORDING TO SEX, OCCUPATION AND EDUCATION LEVEL

\begin{tabular}{|l|l|l|}
\hline Description & Frequency & Frequency Percentage \\
\hline Sex & & \\
\hline Male & 24 & $80 \%$ \\
\hline Female & 6 & $20 \%$ \\
\hline Student & & \\
\hline Engineer & 8 & $26.6 \%$ \\
\hline Manager & 10 & $33.33 \%$ \\
\hline Employee & 0 & $0.0 \%$ \\
\hline Other & 6 & $20 \%$ \\
\hline Education & 6 & $20 \%$ \\
\hline Associates Degree & 11 & \\
\hline Bachelor's Degree & 17 & 36.6 \\
\hline Master's Degree & 2 & $56.6 \%$ \\
\hline PhD & 0 & $6.6 \%$ \\
\hline
\end{tabular}

To obtain the desired result and to get the answer whether our investigate hypothesis was correct or not, we compared the first and second questionnaire responses. The results of this comparison have been evaluated through the T-student test. This gives us the ability to prove or reject the effectiveness of cloud computing technology on quality of service enhancement. This test is based on the variable $D i$ which is calculated by the difference between $X i$ and $Y i(X i$ and $Y i$ are our pair variables here that $X i$ is the answer of a question in the first questionnaire distribution and $Y i$ is the answer of a question in the second questionnaire distribution).

$$
D i=Y i-X i
$$

Now, $D i$ is a random variable and assuming a normal distribution of data and an unknown variance, it has t-distribution. So our test statistic will be as follows:

$$
s d=\sqrt{\frac{1}{(n-1)} \sum(D i-\tilde{d})}
$$

where $S d$ is the standard deviation of " $d$ ", $\mathrm{d}=\mathrm{X}-Y$, is the mean of " $d$ ", and " $n$ " is the sample size.

As seen in the table below, with a bivariate t-test on the questions of the first and the second questionnaire, clear results are obtained. As can be seen, totally, the zero assumption which states that using the new system does not have any effect on improving quality of service is rejected. And we can say that the initial hypothesis has been proven.

One of the important things that draws anyone's attention is that the third question of the questionnaires which is about how easy working with the new system is, has been slightly ignored from the users meaning that they often said that learning how to use this system is not so simple, because typically it is far easier to learn how to use traditional knowledge management systems rather than learning cloud-based systems. That's because nowadays each student uses many email addresses and certainly knows well how to work with them, but it takes time to learn a new system. However, as it is illustrated in Table II, other questions which are the next variables of the problem show significant progress, so it can be clearly seen that the new technology has a more impact on the quality of service through the users

\begin{tabular}{|c|c|c|c|c|c|c|c|c|}
\hline \multicolumn{6}{|l|}{ Paired Differences } & \multirow{3}{*}{$t$} & \multirow{3}{*}{ df } & \multirow{3}{*}{$\begin{array}{l}\text { Sig. } \\
\text { (2-tailed) }\end{array}$} \\
\hline & \multirow[t]{2}{*}{ Mean } & \multirow[t]{2}{*}{ Std. Deviation } & \multirow{2}{*}{$\begin{array}{l}\text { Std. Error } \\
\text { Mean }\end{array}$} & \multicolumn{2}{|c|}{$\begin{array}{l}95 \% \text { Confidence Interval } \\
\text { of the Difference }\end{array}$} & & & \\
\hline & & & & Lower & Upper & & & \\
\hline Pair 1 serq11 - serq21 & 1.933 & 1.230 & .225 & 1.474 & 2.393 & 8.610 & 29 & .000 \\
\hline Pair 2 serq 12 - serq 22 & 1.767 & 1.382 & .252 & 1.251 & 2.283 & 7.003 & 29 & .000 \\
\hline Pair 3 serq13 - serq23 & .467 & 1.525 & .278 & -.103 & 1.036 & 1.676 & 29 & .105 \\
\hline Pair 4 serq $14-$ serq24 & 1.467 & 1.332 & .243 & .969 & 1.964 & 6.030 & 29 & .000 \\
\hline Pair 5 serq 15 - serq 25 & 1.800 & 1.126 & .206 & 1.379 & 2.221 & 8.752 & 29 & .000 \\
\hline
\end{tabular}
rather than before.

\section{RESUltS AND FUTURE ACTIVITIES}

As mentioned before, quality of service is an important factor in measuring the success of an information system. Therefore, it was decided to explore this topic in a knowledge-based organization. The main hypothesis of this study was to know whether setting up a knowledge management service based on cloud technology can satisfy users in terms of quality of service or not. After some investigations we found that the users observed significant differences after the implementation of this service.

Other studies can be conducted later on other aspects of information systems success model and interesting results can be found. For example, an evaluation of user satisfaction factor can be made on knowledge management systems on different platforms.

\section{APPENDIX}

Questions provided to the users [25]:

1) Are the software and the hardware up to date?

2) Is the stability coefficient high in different hours?

3) Have users gained the knowledge of using the system easily?

4) Is this service considering users?

5) Do the knowledge management service providers perform their task well? 


\section{REFERENCES}

[1] L. S. Huang and C. P. Lai, "An investigation on critical success factors for knowledge management using structural equation modeling," Social and Behavioral Sciences, vol. 40, pp. 24-30, 2012.

[2] M. T. Khorshed, A. B. M. S. Ali, and S. A. Wasimi, "A survey on gaps, threat remediation challenges and some thoughts for proactive attack detection in cloud computing," Future Generation Computer Systems, vol. 28, pp. 833-851, 2012.

[3] Nist. [Online]. Available: http://www.nist.gov/

[4] N. Sultan, "Knowledge management in the age of cloud computing and web 2.0: Experiencing the power of disruptive innovations," International Journal of Information Management, vol. 33, no. 1, pp. 160-165, 2012.

[5] H. Takase, I. G. McKineley, J. M. West, T. Kumagai, and M. Akai, "Advanced KMS for knowledge sharing and building confidence in CCS," in Proc. 10th International Conference on Greenhouse Gas Control Technologies, vol. 4, pp. 6202-6209, 2011.

[6] H. Y. Su and Y. C. Lin, "Enhancing knowledge based service quality: A knowledge management perspective," The Service Industries Journal, vol. 26, no. 7, pp. 787-800, 2006.

[7] W. H. DeLone and E. R. McLean, "Information systems success: The quest for the dependent variable," Information Systems Research, vol. 3, no. 1, pp. 60-95, 1992.

[8] W. H. DeLone and E. R. McLean, "Model of information system success: A ten-year update," Journal of Management Information Systems, vol. 19, no. 4, pp. 9-30, 2003.

[9] U. R. Kulkarni, S. Ravindran, and R. Freeze, "A knowledge management success model: Theoretical development and empirical validation," Journal of Management Information Systems, vol. 23, no. 3, pp. 309-347, 2006.

[10] P. B. Seddon, "A respecification and extension of the DeLone and McLean model of IS success," Information Systems Research, vol. 8, no. 3, pp. 240-253, 1997.

[11] Y. S. Wang, H. Y. Wang, and D. Y. Shee, "Measuring e-learning systems success in an organizational context: Scale development and validation," Computers in Human Behavior, vol. 23, no. 4, pp. 1792-1808, 2007.

[12] J. H. Wu and Y. M. Wang, "Measuring KMS success: A respecification of the DeLone and McLean's model," Information \& Management, vol. 43, no. 6, pp. 728-739, 2006.

[13] H. J. Chen, "Linking employees e-learning system to their overall job outcomes: An empirical study based on the IS Success model," Computers \& Education, vol. 55, no. 4, pp. 1628-1639, 2010.

[14] C. S. Ong and J. Y. Lai, "Measuring user satisfaction with knowledge management systems: Scale development, purification, and initial test," Computers in Human Behavior, vol. 23, pp. 1329-1346, 2007.

[15] P. C. Palvia, "A model and instrument for measuring small business user satisfaction with information technology," Information and Management, vol. 31, no. 3, pp. 151-163, 1996.

[16] G. Piccoli, R. Ahmad, and B. Ives, "Web-base virtual learning environment: A research framework and a preliminary assessment of effectiveness in basic IT skills training," MIS Quarterly, vol. 25, no. 4, pp. 401-426, 2001.

[17] M. Alavi, "Managing organizational knowledge," in R. Zmud, Ed., Framing the Domains of IT Management: Predicting the Future through the Past, Cincinnati, OH: Pinnaflex, 2000, pp. 15-28.
[18] F. D. Davis, "Perceived usefulness, ease of use, and user acceptance of IT," MIS Quarterly, pp. 319-340, 1989.

[19] J. H. Wu and Y. M. Wang, "Measuring KMS success: A respecification of the DeLone and McLean's model," Information \& Management, vol. 43, pp. 728-739, 2006.

[20] H. G. Hwang, I. C. Chang, F. J. Chen, and S. Y. Wu, "Investigation of the application of KMS for diseases classifications: A study in a Taiwanese hospital," Expert Systems with Applications, vol. 34, pp. 725-733, 2008.

[21] C. Shyong, M. Y. Day, and W. L. Hsu, "The measurement of user satisfaction with question answering systems," Information \& Management, vol. 46, pp. 397-403, 2009.

[22] E. Walker, "The real cost of a CPU hour," IEEE Computer, pp. 35-40, 2009.

[23] M. Lindner, F. Galan, C. Chapman, S. Clayman, D. Henriksson, and E. Elmroth, "The cloud supply chain: A framework for information, monitoring, accounting and billing," in Proc. 2nd International ICST Conference on Cloud Computing, 2011.

[24] D. F. Furguson and E. Hadar, "Optimizing the IT business supply chain utilizing cloud computing," in Proc. 2011 8th International Conference \& Expo on Emerging Technologies for a Smarter World (CEWIT), 2011, pp. 1-6.

[25] S. Petter and E. R. McLean, "A meta-analytic assessment of the DeLone and McLean IS success model: An examination of IS success at the individual level," Information \& Management, vol. 46, no. 3, pp. 159-166, 2009.

Hamed Rezaei was born in Kermanshah city in the west of Iran on the 22 April 1989. He finished his B.S studies in field of information technology at 2012 and then also completed his M.S degree in field of e-commerce in August 2014. Now he is the chairman of Network and Telecommunications Department of FANAVAR Institute of Technology. Also he is a lecturer of such courses about network technologies and information systems in JAHAD university of Kermanshah and Cybertech Institute of Technology. Now he is the CEO of WVC corporation since 2012. His research interests are in network technologies, cloud computing, information systems and secure protocols.

Behdad Karimi was born in Shiraz, Iran in 1988. He is an information technology student of higher education at the University of Qom, Iran. He received his B.D. from Fasa University in field of software engineering. Behdad Karimi works with business owners, nonprofits and organizations that need to use free publicity in traditional and social media to establish their credibility, enhance their reputation, position themselves as experts, sell more products and services, and promote a favorite cause or issue. His professional interests are focused on social media, cloud servicing, location-based services, social media marketing and data analysis.

Seyed Jamalaldin Hosseini was born in 1985 in Qom at the center of Iran. He finished his bachelor and master degree in filed of industrial engineering in University of Qom respectively and then he completed his doctoral course in Amirkabir University of Technology. Now he is a member of Faculty of Industrial Engineering of University of Qom. His research interests are in knowledge producing and knowledge management. 